\title{
Lexical Phonological Networks in Children with Down Syndrome: An Initial Syllable Similarity Priming Task with an Eye-Tracking Method
}

\author{
Ramos-Sanchez Jessica and Arias-Trejo, Natalia \\ Facultad de Psicología, Universidad Nacional Autónoma de México, México
}

\section{Introduction}

Recent literature with children with typical development (TD) indicates the existence of a structured lexical system based on phonological information since early childhood, with characteristics similar to the ones found in the adult lexical system (Mani \& Plunkett, 2010, 2011). These studies suggest that children have sufficiently differentiated phonological representations that allow for lexical phonological networks to be established. However, in the literature concerning children with Down syndrome (DS) fewer is known on how new words are incorporated into their lexical systems, and the set of principles that guide their lexicons' organization. The present study aims to shed light on whether phonological properties of words are important for the organization of the lexical systems of children with DS.

Previous work has proposed that words that share phonological properties are grouped and linked together to form tight clusters (Arbesman, Strogartz \& Vitevitch, 2010). In the context of word recognition, this clustering of phonologically related words allows for a more efficient word retrieval (Luce \& Pisoni, 1986). This is due to a process in which an auditive input will activate lexical decision units, or lexical candidates, that are interconnected and will compete between each other until one of them becomes recognized as the target word (Neighborhood Activation Model, Luce \& Pisoni, 1998; Cohort Model, Marslen-Wilson \& Moss, 1996; Marslen-Wilson, 1987; TRACE Model, McClelland \& Elman, 1986).

The competitive nature of the word recognition system of adults and children has been studied through phonological priming tasks. For instance, adults were found to show slower recognition times of words when preceded by phonologically related words (i.e., green /gri:n/ - grief /gri:f/) compared to unrelated words (Goldinger et al., 1992; Slowiaczek \& Hamburger, 1992). The authors argue that the interference in the recognition of the target word (priming inhibition effects) in related trials reflect the competitive environment created by the activation of multiple lexical candidates. Further support for this idea comes from studies that show that the level of interference with target recognition is correlated with the number of possible lexical competitors simultaneously activated (Perea \& Rosa, 2000; Dufour \& Peereman, 2003). Research with Spanish-speaking adults by González-Álvarez and Palomar-García (2016) reports, using a lexical decision task, greater error rates and slower times in the recognition of words that start with high-frequency syllables (e.g., casa, cama, calor), and therefore have a greater number of syllabic neighbors, compared to lowfrequency syllables.

The infant phonological priming literature describes similar results to those found for adults. Mani \& Plunkett $(2010,2011)$ evaluated 18 and 24-month-old infants through an Inter-Modal preferential looking task (Golinkoff et al., 1987). They presented infants with an image of a name-known object (prime image) followed by the simultaneous presentation of two images on screen (target and distracter). In half of the trials, the prime and target labels shared phonological similarity in the first consonant (i.e., book /bok/ - bath /ba: $\theta /$ ). In the other half, the prime label was unrelated to both the target and distracter labels. The authors

\footnotetext{
* This work was supported by PAPIIT-IN304417 research grant "Redes Léxicas Tempranas: Análisis Longitudinal en Infantes con Desarrollo Típico y Exploratorio en Población con Síndrome de Down”. We thank all institutions, children and their families who contributed and participated in this study. We also thank the Psycholinguistic's lab team for their assistance on data collection. Correspondence concerning this article should be addressed to Natalia Arias-Trejo, Facultad de Psicología, Universidad Nacional Autónoma de México. E-mail: nariast@unam.mx
} 
found contrasting results for both groups. While the 18-month-olds better recognized the target (i.e., looked longer at the target image) in related trials than unrelated trials, the 24-month-olds showed effects of inhibition in the recognition of the target, by looking less at the target image in related trials than unrelated trials. Mani and Plunkett (2011) suggested the difference in vocabulary size between groups could explain the different pattern of results. The 24-month-olds have larger vocabularies that might require a more efficient organization and clustering of words to facilitate word recognition; likewise, their larger vocabularies allow to create greater competition environments that lead to stronger priming effects. Mayor and Plunkett (2014) further reinforced the idea that an increase in vocabulary size allows for greater competition environments, as they found a significant increase in the number of possible lexical competitors with age.

Fewer is known concerning the lexical organization of children with DS. While receptive vocabulary knowledge is found to be a relative strength in individuals with DS (Abbeduto, Warren \& Conners, 2007; Chapman \& Hesketh, 2001), their phonological abilities could be considered a weakness (Cardoso-Martins, Mervis \& Mervis, 1985; Snowling, Hulme \& Mercer, 2002; Verucci, Meghini \& Vicari, 2006). Moreover, it has been suggested that children with DS have deficits in the phonological component of their short-term memory (Gathercole, Baddeley, 1990; Gathercole et al., 1999). This presents a special problem for individuals with DS, since the stable formation of phonological representations in long-term memory is found to be related with the quality of the phonological representations created in short-term memory (Baddeley, Gathercole \& Papagno, 1998; Burgess \& Hitch, 1999; Gupta, MacWhinney, Feldman \& Sacco, 2003). Evidence that deficits in the verbal short-term memory of individuals with DS hinders the learning of stable phonological representations comes from Jarrold, Thorn and Stephens (2009), who found a correlation between impairments in the verbal-short term memory (evaluated with three tasks: serial recall, item recognition and order recognition) of young adults with DS and their ability to learn the phonological form of new words but not their physical referents.

Furthermore, when children with DS are evaluated with explicit phonological awareness (i.e., alliteration rhyme and phoneme detection, syllable segmentation) tasks lower scores tend to be observed when compared to children with TD either with their same receptive vocabulary or reading ability measures; according to these authors the results suggest less detailed and segmented phonological representations in children with DS compared to their TD peers (Cardoso-Martins et al., 1985; Snowling, Hulme \& Mercer, 2002). Therefore, questions arise on whether the impairments in the learning of stable and detailed phonological representations found in individuals with DS pose limitations in the efficient lexical organization and clustering of words based on phonological similarities.

Possible answers could be found by looking at research with children with Specific Language Impairment (SLI) as these children also show impairments in their verbal short-term memory (Gathercole \& Baddeley, 1990; Weismer, Evans \& Hesketh, 1999) as well as evidence of poorly specified phonological representations (Alt \& Plante, 2006). Gray, Reiser and Brinkley (2012) evaluated children with SLI, and two groups of children with TD: one matched by age and a second matched by vocabulary size, with a phonological priming task using a cued-shadowing paradigm, to study their phonological word-form representations. Children listened to pairs of words and were required to repeat the second word as quickly as they could. Target words were paired with four different types of primes: identical (i.e., bed-bed), overlapping onset (i.e., bed-best), overlapping rhyme (i.e., bed-red) and unrelated (i.e., bed-duck). The authors found no evidence of inhibition for the children with SLI, who had overall the fastest reaction times independent of condition when compared to both the children with TD matched by age and vocabulary size; that is there was no evidence of lexical competition effects interfering with the recognition of the target words for the group with SLI. Hence, Gray, Reiser and Brinkley (2012) results hint that poorly specified phonological representations are related with a less organized lexical system. A phenomenon that could extend to populations with similar phonological deficits as children with SLI, such as children with DS.

Our goal in the present study is to shed light on whether phonological properties of words are important for the organization of the lexical systems of children with DS. We tested children with DS and children with TD paired by vocabulary size with an adaptation of an Inter-Modal preferential looking paradigm (IPL) phonological priming task proposed by Mani and Plunkett (2010, 2011). Children were presented with two priming conditions: a related one were prime and target labels were phonologically related on the first syllable, and an unrelated one. Following the evidence of poorer phonological representations in children with DS we predicted poorer priming effects in this group compared with the group with TD. 


\section{Method}

3.1 Participants. Twenty-four children with DS (mean chronological age $=9.7$ years $[\mathrm{SD}=4.2]$ ) and twenty-four children with TD (mean chronological $=3.1$ years $[\mathrm{SD}=.51$ ) were evaluated. Both groups were paired by their direct scores in the Peabody Picture Vocabulary Test PPVT-III Spanish version (Dunn, Dunn \& Arribas, 2010) to control for vocabulary size; as well as paired by their gender. Inclusion criteria for the DS group were: a) to have a Trisomy 21 diagnostic as reported by parents, b) to successfully pass both a hearing and vision screening test performed at the start of the evaluation, c) to not have any reported oculomotor disorder (e.g., nystagmus or strabismus) at the date of evaluation, as reported by parents, d) to not have any neurological or neurodevelopmental disorder additional to their syndrome. For the TD group inclusion criteria were the same, excluding the Trisomy 21 diagnostic. Table 1 shows the detailed statistics for the comparison between the DS group and TD group. The children with DS were recruited from several institutions and foundations. The typical development children were recruited from a Mexico City childcare facility. 75 children with typical development were evaluated with the PPVT-III Spanish version to obtain the 24 control TD children. 16 additional children with DS were evaluated but failed to pass inclusion criteria.

Table 1.

Group Characteristics

\begin{tabular}{cccc}
\hline & \multicolumn{2}{c}{ Group } & \multirow{2}{*}{$p$} \\
\cline { 2 - 3 } Characteristic & DS & TD & \\
& M(SD) & $3.1(.51)$ & $.000^{\mathrm{a}}$ \\
\hline Chronological Age [CA] (years) & $9.7(4.2)$ & $.100^{\mathrm{b}}$ \\
Mental Verbal Age [MVA] (months) & $40.4(9.4)$ & $40.4(9.4)$ & \\
PPVT III Direct Score & $26.9(10.6)$ & $26.9(10.6)$ & \\
Males (\%) & $17(68 \%)$ & $17(68 \%)$ & \\
Females (\%) & $8(32 \%)$ & $8(32 \%)$ & \\
\hline
\end{tabular}

${ }^{a} p$-value for the t-test between the CA of the DS and TD group

${ }^{\mathrm{b}} p$-value for the t-test between the CA and MVA of the TD group

\subsection{Stimuli}

3.2.1 Lexical stimuli. Thirty concrete, disyllabic nouns were selected from the MacArthur Bates Communicative Development Inventory adapted for Spanish-speaking children with DS (Galeote et al., 2006). From these words 10 were selected exclusively as Primes, 10 as Targets and 10 as Distracters. Twentyseven of the words selected were accentuated on its first syllable, and three were accentuated on the second syllable. The Target-Prime related pairs were defined so that they shared a phonological similarity in the first syllable (initial position). In addition, to distinguish phonological similarity effects, Target-Prime pairs did not belong to the same semantic category and were associatively unrelated (according to Normas de Asociación de palabras para el Español de México, Barrón-Martinez \& Arias-Trejo, 2014).

Prime words were always presented in auditory form, while Target words were presented both in auditory and visual form (through the presentation of the referent image). The Distracter image was never labelled, and its label was phonologically, semantically and associatively unrelated to both the Prime and Target labels. Familiarity values for the Target and Distracter words were obtained from the Wordbank MacArthur CDI data base for 30-month-old Spanish-speaking children (production). Data was available for 18 of the 20 Target and Distracter words used. There was no significant difference between the familiarity of the Target and Distracter words $(t(16)=.691, p=.936)$. A detailed description of Prime-Target-Distracter triads used in related and unrelated trials is shown in Table 2. 
Table 2.

Detailed description of Prime-Target-Distracter triads

\begin{tabular}{|c|c|c|c|c|c|}
\hline Related Prime & Target & $\begin{array}{c}\text { Phonological } \\
\text { similarity } \\
\end{array}$ & $\begin{array}{c}\text { Shared } \\
\text { Phonemes }\end{array}$ & Distracter & $\begin{array}{c}\text { Unrelated } \\
\text { Prime } \\
\end{array}$ \\
\hline radio /'ra.dio/ & rata /'ra.ta/ & $/ \mathrm{ra} /$ & 2 & nube /'nu.be/ & papel /pa.'pel/ \\
\hline papel /pa.'pel/ & patín /pa.'tin/ & $/ \mathrm{pa} /$ & 2 & reloj /re.'lox/ & calle /'ka.je/ \\
\hline pera /'pe.ra/ & perro /'pe.ro/ & /'pe/_ & 2 & dulce /'dul.se/ & carta /'kar.ta/ \\
\hline calle /'ka.je/ & casa /'ka.sa/ & /'ka/_ & 2 & árbol /'ar.bol/ & radio /'ra.dio/ \\
\hline carta /'kar.ta/ & carne /'kar.ne/ & /'kar/__ & 3 & tenis /'te.nis/ & pera /'pe.ra/ \\
\hline cielo /'sie.lo/ & cierre /'sie.re/ & /'sie/_ & 3 & mesa /'me.sa/ & labio /'la.bio/ \\
\hline cubo /'ku.bo/ & cuna /'ku.na/ & /'ku/_ & 2 & peine /'pei.ne/ & cielo /'sie.lo/ \\
\hline labio /'la.bio/ & lápiz /'la.pis/ & /'la/_ & 2 & silla /'si.ja/ & cubo /'ku.bo/ \\
\hline mami /'ma.mi/ & mano /'ma.no/ & /'ma/__ & 2 & coche /ko.tfe/ & plaza /'pla.sa/ \\
\hline plaza /'pla.sa/ & plato /'pla.to/ & /'pla/_ & 3 & tigre /'ti.gre/ & mami /'ma.mi/ \\
\hline
\end{tabular}

3.2.2 Auditive stimuli. Prime and Target audios were produced by a native Mexican Spanish speaker woman, in a child-directed manner. Audios were recorded in a noise isolated room with a Shure MV51 microphone, and were edited to $44,500 \mathrm{HZ}$ to 32 bits. The duration of Prime and Target audios was not statistically different $(t(19)=.702, p=.492)$ (Prime words: Mean duration $=595 \mathrm{~ms}[\mathrm{SD}=63.7 \mathrm{~ms}]$, Target words: Mean duration $=618 \mathrm{~ms}[\mathrm{SD}=75.4 \mathrm{~ms}]$

3.2.3 Visual stimuli. Images used as referents for the Target and Distracter words were selected from public online libraries. A pilot study was conducted to corroborate that all images used were prototypical and that its referred label was not confounded. The criterion of image selection was to be above the 60th percentile for correct label evoked by the 45 children evaluated in a pilot study (mean chronological age $=4.5$ years $[\mathrm{SD}=.72]$. All images had a 360x360 pixels size and were presented side-by-side on screen, separated by 520 pixels $(13.7 \mathrm{~cm})$.

\subsection{Procedure}

3.4.1 Vision and Hearing Screening. Children were evaluated with the Pigassou visual screening test. The test consists of a $33 \times 45 \mathrm{~cm}$ laminae with six rows of drawings decreasing progressively in size and a pile of cards with the same drawings as the laminae placed in front of the children. The test requires children to point at the corresponding card to the drawing asked by the experimenter on the laminae, thus not requiring a verbal answer, facilitating its use with young children and children with intellectual disabilities. The criterion for acceptance was to obtain a score above $70 \%$ of visual acuity (correctly answer to at least the 5th row). A SERBINTER GSI-Corti audiometer was used to evaluate the hearing acuity of children by means of a Distortion Product Otoacoustic Emissions (DPOAEs) testing. The protocol used was a DP test of 4s with 4 frequencies $(1.0,3.0,4.0$ and $5.0 \mathrm{kHz})$. The criterion for acceptance was to obtain a pass score for both ears in the evaluation.

3.4.3 Phonological Priming Task. We presented the children with an adaptation of the experiment used by Mani and Plunkett (2011) employing a similar trial structure. Children were presented with a bimodal (visual-auditory) phonological priming task using an inter-modal preferential looking paradigm (IPL), by means of a Tobii Eye-Tracker X2-30 and a 23-inch LED monitor. All children sat on a small chair about $65 \mathrm{~cm}$ away from the screen. The eye-tracker mounted below the screen recorded children's eye movements. Auditory stimuli were presented through the monitor's loudspeakers. Each child was presented with 10 trials with a total duration of $3,900 \mathrm{~ms}$ each; five related trials and five unrelated trials. In related trials, the Prime and Target word shared a phonological similarity in the first syllable (e.g., /'ra.dio/ - /'ra.ta/). In unrelated trials, the Prime was phonologically unrelated to the Target and Distracter words (e.g., /'sie.lo/ - /'ku.na/). 
Each trial began with the presentation of a centrally located fixation point that remained on screen for about $300 \mathrm{~ms}$; followed by the presentation in auditory form of the Prime word. The offset of the Prime word audio was controlled to always be at the $1100 \mathrm{~ms}$ point, followed by $200 \mathrm{~ms}$ of blank screen (Interstimulus Interval - ISI). At the $1300 \mathrm{~ms}$ point, two images of familiar objects (i.e., Target and Distracter images) appeared simultaneously side-by-side on screen. 50ms after the onset of the images on screen, children were orally presented with the label for the Target word. The analysis window started at the onset of the images on screen $(1300 \mathrm{~ms})$ to the end of the trial $(3900 \mathrm{~ms})$. An example of the temporal distribution of the trials can be seen in Figure 1.

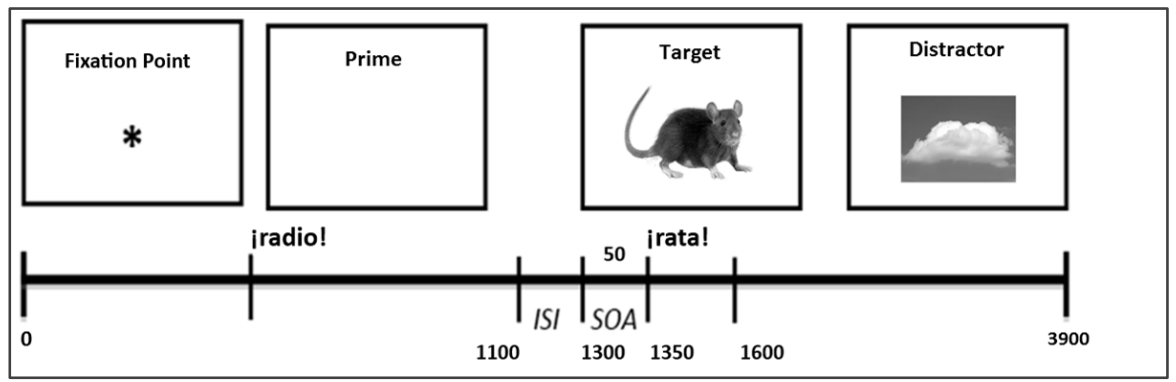

Fig. 1. Temporal Distribution of Trials

Each word was presented only once throughout the experiment. Target-Distracter word pairs were maintained, and appeared with equal frequency across related and unrelated trials, across children. Each participant saw the ten pairs of Target-Distracter images only once. The presentation of the Prime words was counterbalanced so that they appeared with equal frequency in related and unrelated trials, across children. The Target image appeared with equal frequency on the left or right side of the screen, across trials. Order of presentation of trials was randomized within subjects.

3.4.4 Statistical Analyses. Recent literature on Inter-modal preferential looking (IPL) studies in children have hinted the need for a time-course analysis of eye-gaze data, to better understand the time-course manner in which lexical representations are activated (Huettig \& McQueen, 2007; Chow, Davies \& Plunkett, 2017). To perform a temporal analysis of fixation data, we divided our analysis window (1300ms to 3900ms) into thirteen intervals of $200 \mathrm{~ms}$ each. We then calculated the proportion of fixation to the Target image for each time-bin for each type of trial (related-unrelated), for each participant. The proportion (p) of a participant fixating the Target image during a particular time-bin $(200 \mathrm{~ms})$ was calculated as a conditional probability, by counting the number of frames ${ }^{1}$ in which the participant looked at the Target image (T) during the timebin, divided by the total number of frames recorded in the time-bin in which the participant had looked at any of the two images on screen $(\mathrm{N})$ (Target or Distracter), i.e., $\mathrm{p}=\mathrm{T} / \mathrm{N}$. Time-bins in which the participant looked neither to Target or Distracter were not considered in the analyses.

Trials in which the participant had a total looking time to the two images on screen (Target and Distracter) less than $400 \mathrm{~ms}$ were also eliminated from the analyses. Each participant had to provide at least 3 successful related and 3 successful unrelated trials to be considered for the analyses. For the DT group, 102 $(85 \%)$ related trials and $96(80 \%)$ unrelated trials were considered for the analyses from the 240 original trials (120 related and 120 unrelated). For the DS group, 101 (84.1\%) related trials and $94(78.3 \%)$ unrelated trials were considered for analyses, from the 240 original trials (120 related and 120 unrelated). Finally, the trial time-bins of each participant were aggregated by condition creating a participant's time-bin mean, for each of the 13 time-bins, for the two conditions: related and unrelated.

${ }^{1}$ The Tobii X2-30 eye-tracker has a rate of capture of $30 \mathrm{~Hz}$, with an average of 6 frames every 200ms. 


\section{Results}

3.4.3 Time-Course Graphs. Fig. 2 and 3 show the time-course graphs for the proportion of fixation to Target in related and unrelated trials for the TD and DS group. The participant's time-bin means were averaged across participants by condition to obtain the time-course graphs. The time-course pattern of fixation to Target for related and unrelated trials for the group with TD was similar all throughout the analysis window (Fig. 2). One sample t-tests against chance level (.5) were conducted for each time-bin, using Bonferroni adjusted alpha levels of .0038 per test (.05/13). Only the time-bin from $2500 \mathrm{~ms}$ to $2700 \mathrm{~ms}$ (Related: $t(23)=4.137, p<.001$; Unrelated: $t(23)=4.630, p<.001$ ) and the time-bin from 2700 to $2900 \mathrm{~ms}$ (Related: $t(23)=4.379, \mathrm{p}<.001$; Unrelated: $t(23)=4.738, p<.001$ ) showed that children with TD had a proportion of fixation to Target significantly different from chance (.5) for both related and unrelated trials.

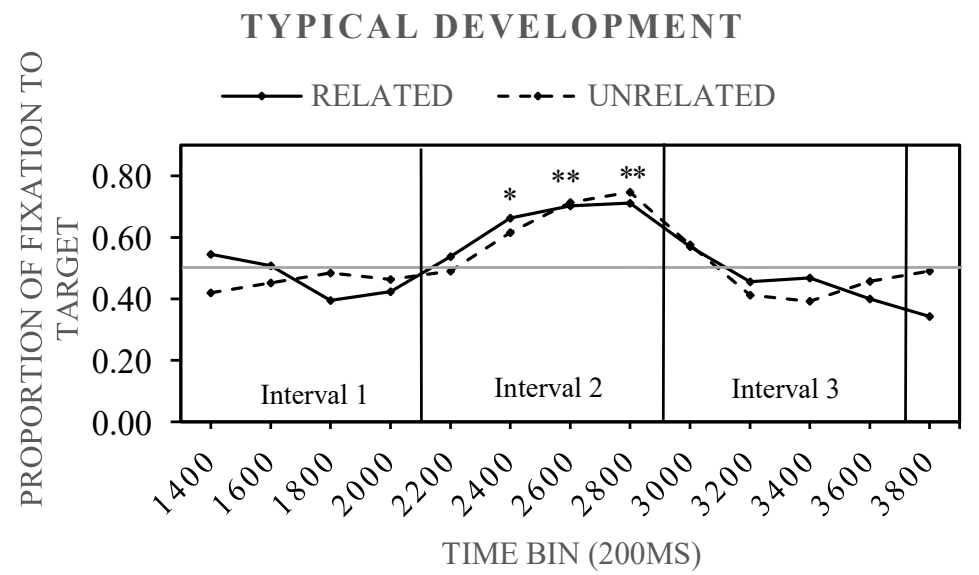

Fig 2. Proportion of fixation to Target, averaged across participants, in related and unrelated trials for each of the 13 time-bins for the TD group

For the group with DS, the time-course pattern of fixation to Target for related and unrelated trials was different throughout the analysis window (Fig. 3). One sample t-tests against chance level (.5) were conducted for each time-bin, using Bonferroni adjusted alpha levels of .0038 per test (.05/13). The proportion of fixation to Target was significantly different from chance level $(0.5)$ for the unrelated trials in the timebins from 2100 to $2300 \mathrm{~ms}(t(23)=4.306, p<.001)$, from 2300 to $2500 \mathrm{~ms}(t(23)=5.365, p<.001)$, from 2500 to $2700 \mathrm{~ms}(t(23)=3.105, p<.003)$ and from 3500 to $3700 \mathrm{~ms}(t(23)=3.251, p<.003)$.

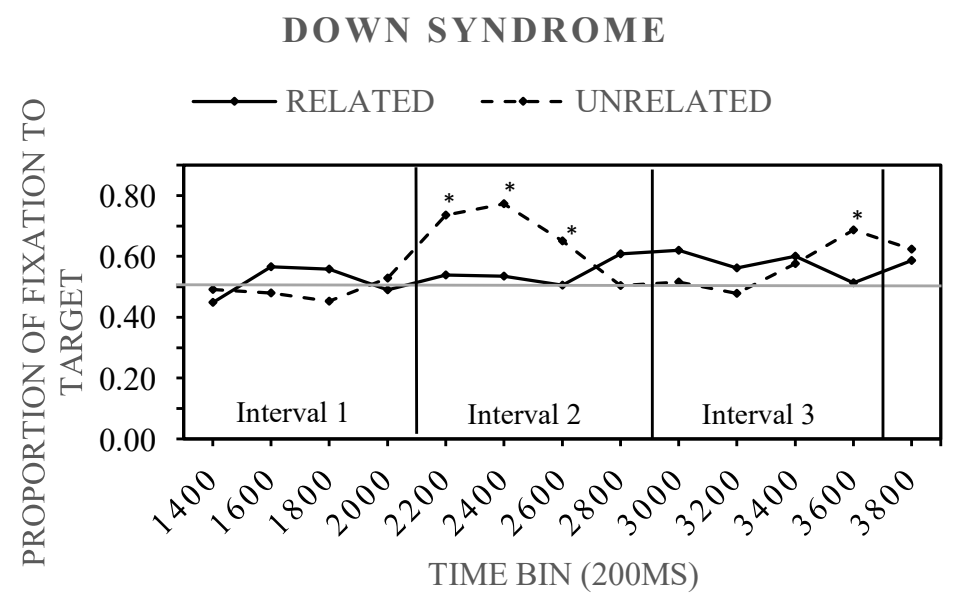

Fig. 3. Proportion of fixation to Target, averaged across participants, in related and unrelated trials for each of the 13 time-bins for the DS group 
3.4.3 Interval analysis. A further interval analysis was conducted by grouping the time-bins in the analysis window into three major intervals, with the data of each participant, for each group. Only twelve of the thirteen original time-bins were considered in order to have the same number of time-bins (4) per interval, per participant ( 4 × $24=96$ time-bins per interval). The three intervals are indicated in Fig. 2 and 3.

- Interval 1: A 'reaction time' interval from the 1300 to $2100 \mathrm{~ms}$.

- Interval 2: A 'recognition of target' interval from the $2100 \mathrm{~ms}$ to $2900 \mathrm{~ms}$.

- Interval 3: An 'exploration of screen' interval from the 2900 to $3700 \mathrm{~ms}$.

With proportion of fixation to Target as dependent variable, we conducted a $2 \times 3$ repeated measures analysis of variance (ANOVA) with Condition (related and unrelated trials) and Interval (Interval 1, 2 and 3) as within-subjects factors, for each group. Partial eta-squared and Cohen's d are reported as effect size measures for main effects, interactions and paired-sample post-hoc t-tests. For the group with TD, the ANOVA with Condition and Interval as within-subjects factors yielded a main effect of Interval $\left(F(2,190)=23.64, p<.001, \eta_{\mathrm{p}}^{2}=.199\right)$. There was no other significant effect; Condition $(F(1,95)=.257$, $\left.p=.613, \eta_{\mathrm{p}}^{2}=.003\right)$, or interaction $\left(F(2,190)=.002, p=.998, \eta_{\mathrm{p}}^{2}=.003\right)$. Post-hoc analyses with pairedsample $t$ tests indicated that, for both related and unrelated trials, only the proportion of fixation to Target in Interval 2 was significantly higher than Interval 1 (Related: $t(95)=5.147, p<.001, d=.509$, Unrelated: $t(95)$ $=4.90, p<.001, d=.498$ ) and Interval 3 (Related: $t(95)=3.855, p<.001, d=.512$, Unrelated: $t(95)=3.88$, $p<.001, d=.424)$, indicating that children with TD recognized the Target with equal ease, independent of the type of trial, specifically during the Interval 2 (2100ms to 2900ms) (Fig. 4).

The ANOVA with Condition and Interval as within-subjects factors yielded, for the group with DS, a main effect of Interval $\left(F(2,190)=5.42, p=.005, \eta_{\mathrm{p}}^{2}=.056\right)$ and a significant interaction between Condition and Interval $\left(F(2,190)=3.75, p=.025, \eta_{\mathrm{p}}^{2}=.040\right)$. Post-hoc analyses with paired-samples $t$-test indicated that, only for the unrelated trials, the proportion of fixation to Target in Interval 2 was significantly higher than Interval $1(t(95)=2.63, p=.010, d=.38)$ and Interval $3(t(95)=2.637, p=.010, d=.258)$. A significant difference in the proportion of fixation to Target between related and unrelated trials was found for the Interval $2(t(95)=2.88, p=.005, d=.378)$. These results suggest that children with DS were able to recognize the Target during Interval $2(2100-2900 \mathrm{~ms})$ but only when Prime and Target words were unrelated (Fig. 4).

TYPICAL DEVELOPMENT

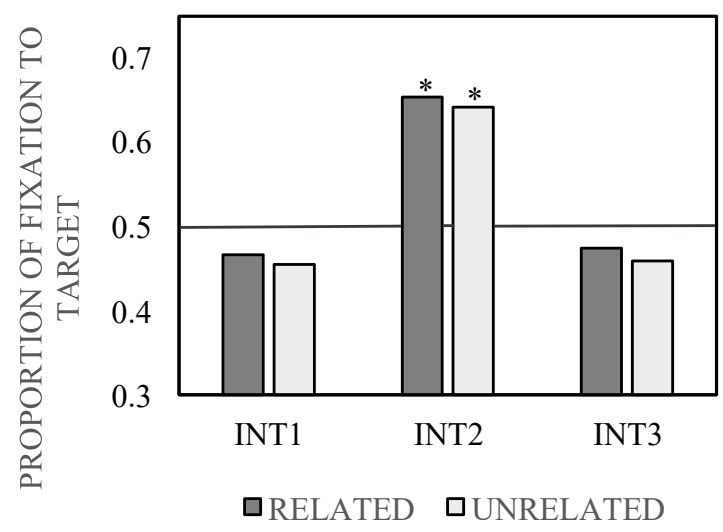

DOWN SYNDROME

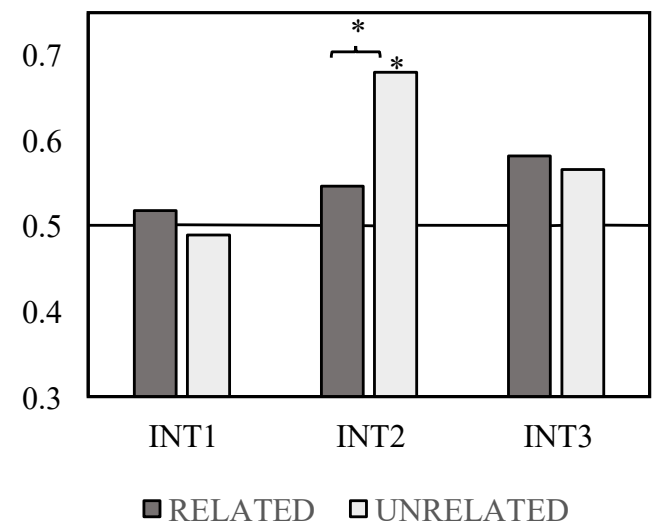

Fig. 4 Proportion of fixation to Target in related and unrelated trials in each of the three Intervals for the group with TD and DS

3.4.4 Cohort analysis. Research with adults (Luce \& Pisoni, 1998; Stamer \& Vitevitch, 2012) and more recently infants (Mani \& Plunkett, 2011) have suggested that words with a greater number of phonologically related words generate greater lexical competition. Hence, in a phonological priming task the presentation of Primes with a higher number of phonologically related words (a larger cohort size) will produce stronger competition effects in the recognition of the Target. Therefore, we analyzed the influence of the Primes cohorts on the children's responding. 
We used the Diccionario Silábico de Frecuencias² (Syllabic Frequency Dictionary) by Justicia, Santiago, Palmas, Huertas and Gutiérrez (1996) to obtain the number of phonologically related words (started with the same initial syllable) to the Prime words. Table 3 shows the division of the Prime words into Primes with a large cohort size (LCS) (/'ma/, /pa/, /'pe/, /'ka/) and a small cohort size (SCS) (/'sie/, /'pla/, /'ku/, /'kar/, /'la/, /'ra/) according to the data obtained. We aggregated the trials with Primes with a small cohort size and the trials with Primes with a large cohort size per condition, per participant. For the analysis, we considered the same Interval division of section 3.4.3.

Table 2.

Prime Cohort Size groups obtained from the Syllabic Frequency Dictionary (Justicia et al., 1996)

\begin{tabular}{ccccc}
\hline \hline Prime Cohort Size & Prime & Target & Initial Syllable & \# Related Words \\
\hline \hline \multirow{3}{*}{ Small Cohort } & Cielo & cierre & /cie/ & 10 \\
$($ SCS $)$ & Plaza & plato & $/ \mathrm{pla} /$ & 30 \\
& Cubo & cuna & $/ \mathrm{cu} /$ & 52 \\
& Carta & carne & $/ \mathrm{car} /$ & 53 \\
& Labio & lápiz & $/ \mathrm{a} /$ & 81 \\
& Radio & rata & $/ \mathrm{ra} /$ & 82 \\
\hline \multirow{2}{*}{ Large Cohort } & Mami & mano & $/ \mathrm{ma} /$ & 200 \\
$($ LCS $)$ & Pera & perro & $/ \mathrm{pe} /$ & 202 \\
& Papel & patín & $/ \mathrm{pa} /$ & 253 \\
& Calle & casa & $/ \mathrm{ca} /$ & 369 \\
\hline
\end{tabular}

Figure 5 depicts the results obtained for the group with TD. To evaluate whether children with TD recognized the Target differently when presented with LCS Primes, we performed one-sample $t$ tests against chance level (.5) for each Interval, per Condition, per Cohort Size, using Bonferroni adjusted alpha levels of .004 per test $(.05 / 12)$. The analyses suggested that when presented with SCS Primes children with TD recognize the Target during Interval $2(2100-2900 \mathrm{~ms})$ in both related $(M=.737, S D=.341 ; t(95)=.816, p$ $<.001, d=.696)$ and unrelated trials $(M=.621, S D=.392 ; t(95)=3.02, p=.003, d=.308)$. Although, they have a significantly greater proportion of fixation to Target in related trials than unrelated trials $(t(95)=8.30$, $p<.001, d=.979)$. However, when presented with LCS Primes children with TD recognize the Target during Interval 2 only in unrelated trials $(M=.671, S D=.320 ; t(95)=5.24, p<.001, d=.535)$. This suggests that the presentation of LCS Primes hinders the ability of children with TD to recognize a phonologically related Target word.

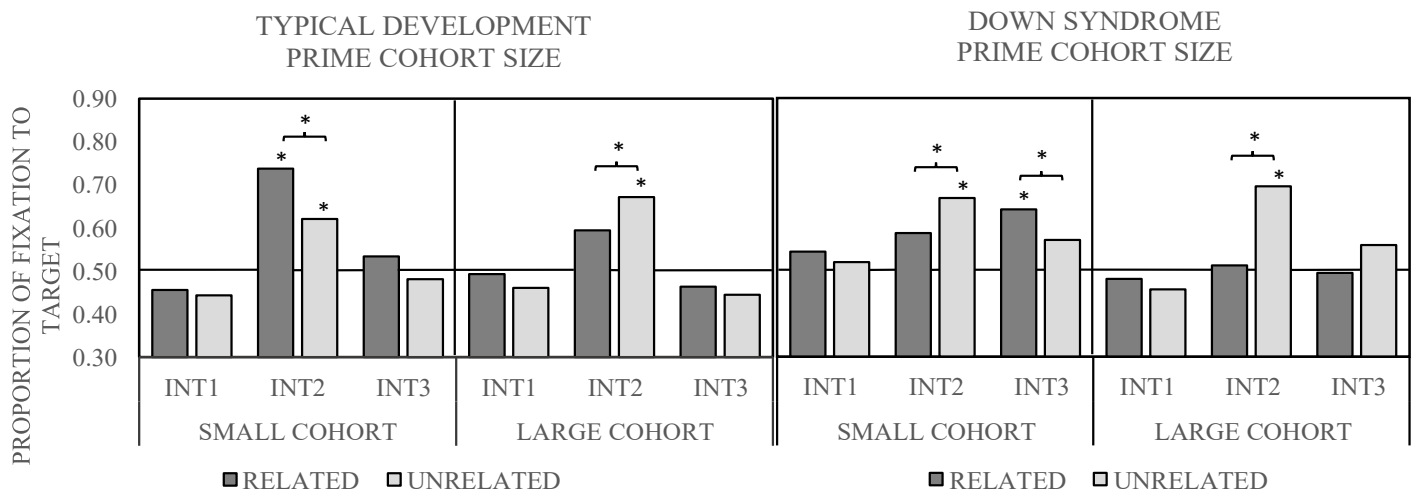

Fig. 5 Proportion of fixation to Target in related and unrelated trials for the group with TD and DS, separated according to prime cohort size.

2 The Diccionario Silábico de Frecuencias was created from a corpus of verbal productions from 2,166 Spanish speaking children aged between 6 and 10 years. 
For the group with DS, similar one-sample $t$ tests against chance level (.5) for each Interval, per Condition, per Cohort Size were performed; using Bonferroni adjusted alpha levels of .004 per test (.05/12). The analyses suggested that when presented with SCS Primes, children with DS recognize the Target in both related $(M=.642, S D=.425 ; t(95)=3.27, p=.001, d=.334)$ and unrelated $(M=.668, S D=.375 ; t(95)=$ $4.37, p<.001, d=.448)$ trials. Although, they recognize the Target in unrelated trials faster (Interval 2) than related trials (Interval 3) (Fig. 5). But when presented with LCS Primes, children with DS, similarly to their TD counterparts, recognize the Target during Interval 2 only in unrelated trials $(M=.695, S D=.369 ; t(95)$ $=5.16, p<.001, d=.527$ ). Results suggest a similar effect than the one found for children with TD. The presentation of Primes with a greater number of phonologically related words (LCS) hinders the ability of children with DS to recognize a phonologically related Target.

\section{Discussion and Conclusions}

Children with DS are thought to have problems in the learning of stable phonological representations, which hinder their word-form learning abilities (Jarrold, Thorn \& Stephens, 2009), and might hamper the organization of their lexical systems. The current study aimed to shed a light on whether phonological properties of words provide a basis for the organization of the lexicons of children with DS. We used an Inter-Modal preferential looking task to examine whether phonologically related words impacted children's Target recognition. Results indicated three main findings: (1) inhibition effects for the group with DS, evidenced by a target preference limited to unrelated trials, (2) evidence of Prime Cohort Size having an impact in the priming effects observed for both groups of children, and (3) an overall absence of priming effects for the group with TD.

We found that children with DS show evidence of inhibition effects in that they recognized the Target only when the Prime and Target words were phonologically unrelated. We interpret this result as evidence of lexical competition taking place during the word recognition process of these children, as Prime words activate a set of lexical competitors that interfere with the processing and recognition of the Target labels. This interference becomes more apparent when Prime and Target labels are phonologically related, therefore hindering the ability of children with DS to correctly recognize the Target label during related trials.

Further support for this interpretation was provided by dividing the trials presented into those with LCS and SCS Primes; as it has been suggested that stronger priming inhibition effects will be seen when using words with a high number of phonologically related words (i.e, cohort size: Marslen-Wilson \& Moss, 1996, González-Álvarez \& Palomar-García, 2016; neighborhood size: Dufour \& Peereman, 2003; Mani \& Plunkett, 2011). In accordance with our prediction, in trials with LCS Primes, children showed a marked interference in the recognition of the Target in related trials; suggesting that the stronger competitive environment produced by these Primes heavily interfered with the Target recognition, particularly when the Target itself was a potential lexical competitor. However, when presented with SCS Primes, children with DS, were able to recognize the Target in both related and unrelated trials. Although, Target recognition in unrelated trials was faster and more robust than in related trials, possibly suggesting a slow down in the recognition of the Target caused by milder lexical competition effects taking place (Fig. 5).

The inhibition and cohort effects observed for children with DS appear to suggest that they do possess sufficiently detailed phonological representations that allow them to efficiently cluster their lexical entries based on their phonological similarities. These results contrast notably with the literature that has explored phonological abilities in children with DS and report the existence of poor phonological representations (Cardoso-Martins, Mervis \& Mervis, 1985; Snowling, Hulme \& Mercer, 2002; Jarrold, Thorn \& Stephens, 2009). A possible explanation for the difference in results comes from the type of task employed in this study compared to the ones that have been previously used. For instance, the phonological awareness and word retrieval tasks used by Jarrold, Thorn and Stephens (2009) required children with DS to make explicit judgments about verbal stimuli; while in this study we used an IPL phonological priming task that pose a lesser cognitive load, and it is reported to tap onto automated cognitive processes (Dufour, 2008). Moreover, the use of an eye-tracking technique has also shown to be advantageous when evaluating individuals with intellectual disabilities as they do not require an explicit verbal or motor response (Brady et al., 2014). The proposal that phonological impairments reported in children with DS are linked to deficits in other cognitive abilities is supported by Nash and Snowling (2002), who found that children with DS generated phonological clusters with a similar size and organization as the ones found for the children with TD, but showed 
difficulties in switching from one cluster to another. The authors argued that the ability to switch between clusters can be detrimentally affected by manipulating attentional load and other executive functions. Therefore, they argued that their findings suggested that children with DS had rich and extensive phonological representations, and that executive deficits were accountable for the word retrieval impairments found in these individuals.

Moreover, Nash and Snowling (2002) found that the cluster more commonly produced by Englishspeaking children with DS was the CV and CVC syllable; suggesting perhaps that children with DS find it easier to cluster their words using phonological similarities at the syllable-level. Our results appear to support this idea, as they show that a phonological similarity between prime and target words at the level of the initial syllable is enough to produce inhibition effects in the recognition of the target in our Spanish-speaking children with DS. However, as we did not manipulate the amount of phonological similarity between prime and target words, we cannot rule out the possibility that inhibition effects will also be found using a phonological similarity between prime and target words at the level of one single phoneme.

An unexpected result was obtained for the group with TD. While the results by Mani and Plunkett (2010, 2011) indicate that 21-month-old infants show priming inhibition effects, suggested to be caused by their greater vocabulary size; our results show an absence of priming effects. In our study, children with TD recognized the Target with equal ease independent of the type of trial. There are two possible explanations for the difference in results, one developmental and the second methodological. Mani and Plunkett (2010) evaluated children with an average chronological age of 21 months; while we evaluated children with an average chronological age of 37 months. There is some evidence of a developmental change in the way phonological, lexical (i.e., cohort/neighborhood sizes) and semantic variables have in word learning in infants. According to Storkel (2009), the creation of many lexical connections (based on neighborhood density or word frequency) facilitates word learning until around the age of 21 months but then slowly diminishes, giving rise to a preference on creating semantic connections between words. Therefore, it is possible that the children evaluated in the present study have greater vocabulary sizes than the 21 -montholds evaluated by Mani and Plunkett (2010), and need a more robust lexical network that starts incorporating other word properties such as semantic or associative variables, that might outweigh the phonological-lexical ones.

However, it should also be noted that in this study disyllabic words were used as opposed to the monosyllabic words used by Mani and Plunkett (2010) due to early vocabularies of Spanish speaking children consisting largely of disyllabic words, opposite to the early vocabularies of English-speaking children. The incorporation of a second syllable in our study added 300 to the $200 \mathrm{~ms}$ of ISI (Inter-Stimuli Interval). Hence, the time between the offset of the initial syllable of the Prime and the onset of the initial syllable of the Target was on average of 500ms. Goldinger et al. (1992) have indicated that inhibition effects disappear by increasing the ISI times from $50 \mathrm{~ms}$ to $500 \mathrm{~ms}$. This is thought to be caused by the transient nature of the lexical competition effects in phonological priming; with larger ISI times the activation of lexical competitors dissipates before the presentation of the Target word (Goldinger et al., 1992). However, it should be noted that in the present study inhibition priming effects were found for the children with DS even with this large ISI time. While differences in the speed of processing of verbal stimuli between groups could be used to explain the distinct results, our time-course analysis reveals that speed processing of verbal stimuli appeared to be similar between groups. As can be seen in Fig. 2 and 3, children with TD and DS, in unrelated trials, showed proportions of fixation to Target different to chance level (.5) at similar time points, with children with DS being surprisingly faster than TD children at recognizing the Target in those trials.

Hence, a second explanation for our results is that other processes, such as lateral inhibition, account for the absence of priming affects observed in the group of TD, and the strong inhibition effects seen in the group with DS. Word recognition models such as TRACE (McClelland \& Elman, 1986) include a process in which activated lexical candidates are interconnected and compete between each other by means of lateral inhibition; and the lexical entry that more strongly inhibits the others becomes recognized. It is not implausible that children with TD are more efficient at dealing with the competitive environments created by the presentation of phonologically similar words, while children with DS have more difficulties at inhibiting the lexical competitors and therefore take longer to recognize the target in related trials. Possible evidence for this idea can be seen in the analysis of Prime cohort size. Children with TD when presented with SCS Primes can quickly deal with the lexical competition and recognize the Target efficiently in both type of trials. Only LCS Primes, that create stronger levels of lexical competition, poses difficulty for children with 
TD, hence inhibition effects are seen for these trials (Fig. 5). On the other hand, children with DS still show effects of inhibition for the trials with SCS Primes in the form of a slower recognition of the Target; suggesting that even milder lexical competition effects difficult the recognition of the Target for these children. Further evidence comes from studies that have shown an impaired ability of children with DS to inhibit irrelevant information in Stroop tasks (Borella, Carretti \& Lanfranchi, 2013). While these tasks have been used as diagnostic markers for impairments in executive functions, they have been recently found to also reveal differences in the speed and efficiency of lateral inhibition between mental representations (Naber, Vedder, Brown \& Nieuwenhuis, 2016).

Nonetheless, the finding of priming inhibition effects and lexical competition effects suggest an efficient word recognition system of DS children. McClelland and Elman (1986), and Luce and Pisoni (1998) have suggested that the existence of lexical competition allows for a more flexible lexical retrieval that is resistant to ambient noise, bad clarity of acoustic input among other acoustic ambiguities. Furthermore, the presence of cohort size effects suggests a pattern of lexical acquisition in children with DS sensible to the phonotactic characteristics of their language, that allows for the clustering of words based on phonological similarity.

In conclusion, our study gives evidence of phonological priming and cohort effects in word recognition in children with TD and DS. However, conclusions of the current study should be considered in light of its limitations. The lack of manipulation of ISI times does not allow us to answer for the absence of inhibition in the group with TD. Further research should attempt to demonstrate if reducing ISI times will allow for priming effects to be seen. A second limitation is the difficulty to control for Prime and Target cohort sizes when working with early vocabularies, since there is an ongoing debate on whether competition effects are lead by the Target or Prime cohort size (Dufour \& Peereman, 2003; Mani \& Plunkett, 2010).

\section{References}

Abbeduto, L., Warren, S. F., \& Conners, F. A. (2007). Language development in Down syndrome: from the prelinguistic period to the acquisition of literacy. Mental Retardation and Developmental Disabilities Research Reviews, 13, 247-261.

Alt, M., \& Plante, E. (2006). Factors that influence lexical and semantic fast mapping of young children with specific language impairment. Journal of Speech, Language, and Hearing Research, 49(5), 941-954.

Arbesman, S., Strogartz, S. H., \& Vitevitch, M. S. (2010). The structure of phonological networks across multiple languages. International Journal of Bifurcation and Chaos, 20(3), 679-685.

Baddeley, A., Gathercole, S., \& Papagno, C. (1998). The Phonological Loop as a Language Learning Device. Psychological Review, 105(1), 158-173

Barrón-Martinez, J. B., \& Arias-Trejo, N. (2014). Word association norm in Mexican Spanish. The Spanish Journal of Psychology, 17, E90, 1-13

Borella, E., Carretti, B., \& Lanfranchi, S. (2013). Inhibitory mechanisms in Down syndrome: Is there a specific or general deficit? Research in developmental disabilities, 34(1), 65-71.

Brady, N. C., Anderson, C. J., Hahn, L. J., Obermeier, S. M., \& Kapa, L. L. (2014). Eye tracking as a measure of receptive vocabulary in children with autism spectrum disorders. Augmentative and Alternative Communication, 30(March 2013), 147-59.

Burgess, N., \& Hitch, G. J. (1999). Memory for serial order: A network model of the phonological loop and its timing. Psychological Review, 106(3), 551-581.

Cardoso-Martins, C., Mervis, C. B., \& Mervis, C. A. (1985). Early vocabulary acquisition by children with Down syndrome. American Journal of Mental Deficiency, 90(2), 177-184.

Chapman, R. S., \& Hesketh, L. J. (2001). Language, cognition, and short-term memory in individuals with Down syndrome. Down Syndrome Research and Practice, 7(1), 1-7.

Chow, J., Davies, A. A., \& Plunkett, K. (2017). Spoken-word recognition in 2-year-olds: The tug of war between phonological and semantic activation. Journal of Memory and Language, 93, 104-134.

Dufour, S. (2008). Phonological priming in auditory word recognition: When both controlled and automatic processes are responsible for the effects. Canadian Journal of Experimental Psychology, 62(1), 33-41

Dufour, S., \& Peereman, R. (2003). Inhibitory priming effects in auditory word recognition: when the target's competitors conflict with the prime word. Cognition, 88(3), B33-B44.

Dunn, L. M., Dunn, L. M., \& Arribas, D. (2010). Peabody-III. Test de vocabulario en imágenes. Madrid: Editorial TEA.

Galeote, M., Soto, P., Serrano, A., Pulido, L., Rey, R., \& Martinez-Roa, P. (2006). Un nuevo instrumento para evaluar 
el desarrollo comunicativo y lingüístico de niños con síndrome de Down. Investigación, 23, 21.

Gathercole, S., \& Baddeley, A. (1990). Phonological memory deficits in language disordered children: Is there a causal connection? Journal of Memory and Language, 29(3), 336-360.

Goldinger, S. D., Luce, P. A., Pisoni, D. B., \& Marcario, J. K. (1992). Form-based priming in spoken word recognition: The roles of competition and bias. Journal of Experimental Psychology: Learning, Memory and Cognition, 18(6), 1211.

Golinkoff, R. M., Hirsh-Pasek, K., Cauley, K. M., \& Gordon, L. (1987). The eyes have it: lexical and syntactic comprehension in a new paradigm. Journal of Child Language, 14(01), $23-45$.

González-Alvarez, J., \& Palomar-García, M. A. (2016). Syllable Frequency and Spoken Word Recognition. And Inhibitory Effect. Psychological Reports, 119(1), 263-275.

Gray, S., Reiser, M., \& Brinkley, S. (2012). Effect of onset and rhyme primes in preschoolers with typical development and specific language impairment. Journal of Speech, Language, and Hearing Research, 55(1), 32-44.

Gupta, P., MacWhinney, B., Feldman, H. M., \& Sacco, K. (2003). Phonological memory and vocabulary in children with focal lesions. Brain and Language, 87(2), 241-252.

Huettig, F., \& McQueen, J. M. (2007). The tug of war between phonological, semantic and shape information in language-mediated visual search. Journal of Memory and Language, 57(4), 460-482.

Jarrold, C., Thorn, A. S. C., \& Stephens, E. (2009). Journal of Experimental Child The relationships among verbal shortterm memory, phonological awareness, and new word learning: Evidence from typical development and Down syndrome. Journal of Experimental Child Psychology, 102(2), 196-218.

Justicia, F., Santiago, J., Palma, A., Huertas, D., \& Gutiérrez, N. (1996). La frecuencia silábica del español escrito por niños: estudio estadístico. Cognitiva, 8(2), 131-168.

Luce, P. a, \& Pisoni, D. B. (1998). Recognizing Spoken Words: The Neighborhood Activation Model. Ear and Hearing, 19(1), 1-36.

Mani, N., \& Plunkett, K. (2010). In the infant's mind's ear: evidence for implicit naming in 18-month-olds. Psychological Science: A Journal of the American Psychological Society / APS, 21(7), 908-913.

Mani, N., \& Plunkett, K. (2011). Phonological priming and cohort effects in toddlers. Cognition, 121(2), 196-206.

Marslen-Wilson, W., \& Moss, H. E. (1996). Perceptual distance and competition in lexical access. Journal of Experimental Psychology: Human Perception and Performance, 22(6), 1376.

Marslen-Wilson, W. (1987). Functional parallelism in spoken word-recognition. Cognition, 25(1), 71-102.

Mayor, J., \& Plunkett, K. (2014). Infant word recognition: Insights from TRACE simulations. Journal of Memory and Language, 71(1), 89-123.

McClelland, J. L., \& Elman, J. L. (1986). The TRACE model of speech perception. Cognitive psychology, 18(1), 1-86.

Naber, M., Vedder, A., Brown, S. B., \& Nieuwenhuis, S. (2016). Speed and lateral inhibition of stimulus processing contribute to individual differences in Stroop-task performance. Frontiers in psychology, 7: e822

Nash, H. M., \& Snowling, M. J. (2008). Semantic and phonological fluency in children with Down syndrome: Atypical organization of language or less efficient retrieval strategies? Cognitive Neuropsychology, 25(5), 690-703.

Perea, M., \& Rosa, E. (2000). Repetition and form priming interact with neighborhood density at a brief stimulus onset asynchrony. Psychonomic Bulletin \& Review, 7(4), 668-677.

Pisoni, D. B., \& Luce, P. A. (1986). Speech perception: Research, theory and the principal issues. Pattern recognition by humans and machines: Speech perception, 1, 1-50.

Slowiaczek, L. M., \& Hamburger, M. B. (1992). Prelexical Facilitation and Lexical Interference in Auditory Word Recognition. Journal of Experimental Psychology: Learning, Memory and Cognition, 18(6), 1239-1250.

Snowling, M. J., Hulme, C., \& Mercer, R. C. (2002). A deficit in rime awareness in children with Down syndrome. Reading and Writing: An Interdisciplinary Journal. 15(5-6), 471-495

Stamer, M. K., \& Vitevitch, M. S. (2012). Phonological similarity influences word learning in adults learning Spanish as a foreign language. Bilingualism: Language and Cognition, 15(3), 490-502.

Storkel, H. L. (2009). Developmental differences in the effects of phonological, lexical and semantic variables on word learning by infants. Journal of Child Language, 36(2), 291-321.

Verucci, L., Menghini, D., \& Vicari, S. (2006). Reading skills and phonological awareness acquisition in Down syndrome. Journal of Intellectual Disability Research, 50(7), 477-491.

Weismer, S. E., Evans, J., \& Hesketh, L. J. (1999). An examination of verbal working memory capacity in children with specific language impairment. Journal of Speech, Language, and Hearing Research, 42(5), 1249-1260. 